\title{
La conciliación extrajudicial en el Perú, como medio para promover una cultura de paz
}

Rosely E. Shirakawa Okuma

El tema de la conciliación extrajudicial en el Perú, ha adquirido singular importancia a raíz de la promulgación de la Ley № 26872 - Ley de Conciliación extrajudicial y su Reglamento. Sin embargo, la falta de difusión y promoción de este mecanismo alternativo de resolución de conflictos, así como de sus principales objetivos, puede convertirse en un obstáculo para su adecuada implementación y desarrollo.

En principio, se ha generado ya una prórroga de la conciliación hasta el año 2001, al encontrarse que el número de centros de conciliación autorizados en el país es insuficiente para asumir la carga judicial que ingresan a los juzgados. ¿A qué se debió este problema? ¿no es justamente la falta de difusión y promoción de este mecanismo? Entendemos que nos hallamos en una primera etapa de «implementación" de la conciliación, por lo que consideramos que esta labor de difusión y promoción debe ser asumida no sólo por aquellos que la plantearon legalmente sino también por todos los que, de alguna manera, nos encontramos comprometidos con la búsqueda de una cultura de paz en el país.

¿Por qué hablar de una cultura de paz en el país? Porque la conciliación en el Perú se presenta como un mecanismo mediante el cual el particular reconoce su capacidad de solucionar sus conflictos, es decir, se presenta no sólo como una alternativa de comportamiento a nivel pre-judicial, sino que se busca introducir en la sociedad un modelo de relaciones humanas basadas en la convivencia, cooperación y el respeto de los derechos humanos. El artículo $2^{\circ}$ de la Ley de Conciliación Extrajudicial lo establece expresamente: "[...] propicia una cultura de paz $[\ldots] \%$. 
Pero, ¡es éste el verdadero fundamento de la conciliación en el Perú? ¿Cómo se puede «propiciar una cultura de paz» a través de este mecanismo alternativo de resolución de conflictos? Ambas son preguntas que se quedan en el tintero cuando nos encontramos con este artículo $2^{\circ}$ de la Ley de Conciliación. Si bien este objetivo está planteado, nos encontramos con vacíos para su aplicación, por lo que a través de nuestra labor como conciliadores nos corresponde ayudar a cerrar las brechas o construir los puentes necesarios para alcanzar, en la práctica, o por lo menos sentir que nos dirigimos hacia allí, el objetivo esencial de la Conciliación, tal como se ha planteado en la Ley: propiciar una cultura de paz.

En ese sentido, en el presente artículo se intenta presentar la relación que hay entre la figura de la conciliación y la tan mencionada cultura de paz, a fin de colaborar de alguna forma en la labor de difusión y promoción de la conciliación como forma de aproximar a la justicia a las personas, mediante el reconocimiento de todas y cada una de las personas como sujeto de derechos, así como el reconocimiento de uno mismo como partícipe activo de una nueva cultura de paz.

Para empezar, deseamos hacer un análisis sobre la necesidad de buscar nuevas formas de resolución de conflictos, como medio para "propiciar una cultura de paz” ¿Por qué se torna necesaria esta búsqueda?

La generalizada crisis en el Poder Judicial ha conducido a la mayoría de los países a buscar vías que le permitan lograr una renovación de su judicatura. A pesar de las distintas realidades nacionales, se observa que existe una misma orientación de búsqueda de fórmulas que ayuden a solucionar la crisis generada en sus instituciones judiciales. En pocas palabras, el Poder Judicial se ha vuelto insuficiente para satisfacer los intereses de la población de manera adecuada. En ese sentido, se busca trasladar el manejo de los conflictos a las personas privadas, a fin de descargar de alguna forma al Poder Judicial. La conciliación preproceso, "[...] en lo posible, trata de evitar el conocimiento, tramitación y fallo de una causa por el Juez [...] es mucho más conveniente para el Estado, y en particular para el Poder Judicial la conciliación entre las partes, antes de entablar una demanda y seguir un proceso costoso, engorroso y lentom. ${ }^{1}$

1 Feliciano Almeida Peña, La conciliación en la administración de justicia. pp.55-56. 
En el Perú, por ejemplo, el costo de los procesos judiciales, tanto en tiempo como en el aspecto económico, son bastante altos y por lo tanto desalentadores, la tradicional forma de alcanzar justicia es insuficiente y no logra satisfacer las necesidades de la sociedad, lo cual hace difícil que un Estado de Derecho logre mantener su estabilidad. Según Ibrahim Shihata, ${ }^{2}$ "[...] sin un Poder Judicial independiente y honesto, el desarrollo económico y social corre riesgo de hacerse pedazos [...]", de allí la necesidad y urgencia de los países en buscar modernizar los sistemas judiciales.

En ese sentido, ¿qué elementos deben de considerarse para una verdadera modernización de un sistema judicial? Edgar Buscaglia ${ }^{3}$ en su ensayo «Los principales obstáculos de la reforma judicial en América Latina", propone los siguientes:

- Mejoras en la administración de justicia.

- El fortalecimiento de la independencia judicial.

- El desarrollo de mecanismos alternativos de resolución de disputas.

- La mejora de la educación legal de los jueces, abogados y público en general.

- La creación de nuevos canales para facilitar el acceso a la justicia a la población.

Una verdadera reforma judicial, por lo tanto, debería estar orientada hacia el desarrollo de los elementos mencionados, entre los cuales figuran los mecanismos alternativos de resolución de disputas y la creación de nuevos canales de acceso a la justicia. En esa misma línea, Siles Vallejos manifiesta que, «[...] se vienen extendiendo rápidamente proyectos para derivar una serie de asuntos litigiosos y no litigiosos a instancias no jurisdiccionales de resolución de disputas. El recurso a los mecanismos de mediación, conciliación, amigable composición, arbitraje se hace cada vez más común, aparece como uno de los principales remedios a la saturación de la judicatura y a su incapacidad o dificultad

2 Ibrahim Shibata, (1997), En Siles Vallejos Modernización y reforma de los sistema de justicia en América Latina y el Caribe.

3 Edgar Buscaglia (1997). "Los principales obstáculos de la reforma judicial en América Latina”. En: Edmundo Joaquín y Fernando Carrillo (eds.), La Economía Política de la reforma judicial, New York, Banco Interamericano de Desarrollo. (BID), pp. 31-51. 
inveteradas para atender la totalidad de controversias que se presentan $[\ldots] »{ }^{4}$

En este contexto, la conciliación como mecanismo alternativo de resolución de conflictos, se presenta beneficioso a efecto de evitar que las partes tengan que recurrir a esta pesada maquinaria judicial y puedan satisfacer sus intereses de manera eficiente. En ese sentido, los beneficios que presenta la figura de la conciliación extrajudicial es entendida por la mayoría como idónea para lograr dichos fines. Sin embargo, se presentan discrepancias respecto a la forma en la que esta figura ha sido regulada en el país.

En el Perú la conciliación, se presenta como obligatoria a partir del año 2001. Entendemos que esta exigencia tiene como justificación el rol activo del Estado peruano en la sociedad, ya que busca a través de esta obligatoriedad un cambio de cultura en el país. Se ha considerado a este cambio, como todo cambio en la sociedad, difícil si no se presenta a la conciliación como figura obligatoria, ya que lo que se busca es concientizar a las personas de los beneficios que pudieren obtener mediante su utilización y, por otro lado, hacer que las propias personas se reconozcan como partícipes de esta forma pacífica de resolución de conflictos. Una vez logrado dicho cambio de concepción, el sólo conocimiento de los beneficios de esta institución podrá otorgar las herramientas suficiente para decidir acudir a ella de manera voluntaria. Sin embargo, como manifestáramos al inicio, la conciliación no se agota en este nivel, y por lo tanto la labor del Estado tampoco debería agotarse exigiendo únicamente su obligatoriedad. Por el contrario, la construcción de una verdadera cultura de paz en el país, exige una sólida política de educación, así como cambios de fondo en las estructuras de la sociedad. De este modo, la Ley de Conciliación extrajudicial es sólo un paso.

Si bien el marco está dado, existe aún mucho por hacer. La conciliación es una manera de generar caminos de entendimientos y de desarrollo social y personal. Por eso, evitar los conflictos no es la solución al problema que nos aqueja, pues los conflictos se presentan continuamente y de distintas maneras en nuestras vidas. Es de acuerdo a como uno asuma el conflicto que podemos cerrar las brechas o construir los puentes a lo que hacíamos referencia líneas arriba. William

4 Siles Vallejo, Abraham, Op. cit., p. 91. 
Ury, en su conferencia en Buenos Aires, el 1 de julio de 1998, manifestó lo siguiente «[...] el camino no es eliminar al conflicto. El mundo, de hecho, necesita más conflictos y no menos, porque en la medida en que hay injusticia en el mundo vamos a necesitar conflictos para llamar la atención sobre las injusticias. El desafío no está en eliminar el conflicto sino en transformar la forma en que nosotros manejamos el conflicto, que lo hacemos en forma destructiva a través de la violencia, de la guerra, de batallas, etc., de transformarlo en una forma más constructiva como la negociación, la mediación, etc.», y ello, entendemos, está referido a todos los niveles de relación humana.

La conciliación, por lo tanto, no se agota en la descongestión del Poder Judicial, ni en la oportunidad de solucionar el problema laboral de algunos. Sus alcances son mayores, tal como lo dice la ley: «propiciar una cultura de paz». Esperemos que no sean pocos los conciliadores los que tengan presente en el desarrollo de su actividad, la importancia de la función que se encontrarán ejerciendo y hacia donde se encuentra encaminada. 